\title{
Effectiveness of use of Nanostructure Minerals - Bentonite of Taganskiy Deposit for Waste Water Clearing in Metallurgy Industry
}

\author{
${ }^{1}$ Muzdybayeva Sh., ${ }^{2}$ Musabekov K., ${ }^{1}$ Muzdybayev N., ${ }^{2}$ GAskarova G., \\ ${ }^{1}$ Nurbaeva N., ${ }^{2}$ Taybaeva P.
}

\begin{abstract}
The currently used traditional method of waste water treatment based on the precipitation of heavy metals by iron hydroxide formed at the time of neutralization (liming) / bleach (active chlorine) doesn't correspondent to the standards of maximum permissible concentration (MPC) in practical meaning. In this regard, the urgent task is the use of natural materials as sorbents due to the relatively high sorption capacity, selectivity, having cation-exchange properties and the possibility of almost complete removal of heavy metal ions. Another important factor is their relatively low cost and availability (sometimes as a local material). We believe that the use of scientific-based combinations of different ways in waste water treatment based on the success of modern chemistry allows opening new and perspective opportunities in this area.
\end{abstract}

Key Words: Waste Water, Metallurgy, Bentonite, Zeolites, Groundwater

\section{Introduction}

According to assessment of the investment climate UN extraction and refining of raw materials is a permanent factor affecting the flora and fauna. One of the factors of negative influence on the ecological situation at the regional level is the waste water (WW) or so-called mine water (MW), which are formed during mine operating. MW of polymetallic deposits are originally natural groundwater contaminated with particles of rocks, mineral salts, the cations of heavy metals (HM), many times exceeding the maximum permissible concentration (MPC) for normal fishery. Traditional methods of wastewater treatment based on the HM ion precipitation, suspended by particles iron hydroxides, aluminum, which is formed during the neutralization are not universal and do not always achieve the MPC of harmful impurities, especially for water Use of natural materials in a national economy - such as bentonite, zeolites, etc. requires a detailed study of the adsorption, catalytic, bleaching properties in terms of clarifying the possibilities of using clay in chemical, petroleum, food and metallurgical industries. That allows to use them as a sorbent for purification of water from ions of heavy metals, oil products and other toxic contaminants.

In this context, the issue of new advanced techniques development designed for highly efficient purification of industrial water from the HM ions to the level of MPC is particularly relevant. The use of natural materials as sorbents due to relatively high 
sorption capacity, selectivity, cation exchange, having unusual properties and the possibility of almost complete ion HM exception is a very urgent task in addressing environmental issues [5-7].

We believe that the use of natural material - bentonite in the MW purification, based on achievements of modern chemistry, helps to open up new opportunities.

\section{Materials and Methods}

The subject of study is the mine water of East Kazakhstan (EK) Belousovsky polymetallic deposit. The constitution of MW, taken from the treatment plant retention ponds, is presented in Table 1.

Table 1. Characteristics of East Kazakhstan Belousovsky Deposit polymetallic mine water.

\begin{tabular}{|c|c|l|c|}
\hline Components & \multirow{2}{*}{$\mathrm{MPC}}$, & \multicolumn{2}{|c|}{ Proportions, $\mathrm{mg} / \mathrm{dm}^{3}$} \\
\cline { 3 - 4 } & $\mathrm{mg} / \mathrm{dm}^{3}$ & In precipitation & In filtrate \\
\hline $\mathrm{Cu}^{2+}$ & 0,001 & $8,20 \pm 0,20$ & $0,21 \pm 0,04$ \\
\hline $\mathrm{Pb}^{2+}$ & 0,10 & $4,80 \pm 0,16$ & $0,11 \pm 0,03$ \\
\hline $\mathrm{Cd}^{2+}$ & 0,005 & $0,25 \pm 0,02$ & $0,17 \pm 0,02$ \\
\hline $\mathrm{Zn}^{2+}$ & 0,01 & $67,10 \pm 0,63$ & $12,3 \pm 0,39$ \\
\hline Suspended materials & $\begin{array}{l}\text { Not more than } \\
50,00\end{array}$ & 260,00 & 50,00 \\
\hline
\end{tabular}

The results of diagnostic leach showed (Table 2) that the MW dispersed phase has the following constitution: $17 \%$ of chloride, $\sim 52 \%$ of glist, $\sim 26 \%$ of quartz, spars $\sim$ $5 \%$ (by weight).

It is known that the aluminosilicate skeleton of clays, mainly consists of alternating parallel two-dimensional layers formed by silicate tetrahedra and octaedras. The location of these layers, the extent and nature of the replacement within them largely determine the chemical and physical properties of the corresponding materials. The free hydroxyl group can exchange anions when the sorbent is immersed into a solution of. In such clays of replacement both tetrahedral and octahedral layers can occur [7-10].

Silica tetrahedral groups are in the form of endlessly repeating hexagonal grid, making a layer of $\mathrm{Si}_{4} \mathrm{O}_{6}(\mathrm{OH})_{4}$. There are oxygen atoms in the form of laced net mesh at the first level. There are the silicon atoms at the second level. Each of them lies in a excavation formed by three contiguous oxygen atoms of the first level, so that form a hexagonal grid. At the third level, there are hydroxy groups and each hydroxyl group is located at the top of the tetrahedron just above the silicon atom.

\section{Results and Discussion}

The results of MW purification from heavy metal ions $\left(\mathrm{Cu}^{2+}, \mathrm{Pb}^{2+}, \mathrm{Cd}^{2+}, \mathrm{Zn}^{2+}\right)$ with the help bentonite, in natural and activated forms presented in table 2 shows, that the degree of extraction with the help of natural bentonite is $33.3 \%, 18.2 \%, 176 \%$, $29.2 \%$, respectively. This does not provide MPC of HM ions in the water for fish farming purposes. 
Heat treatment of bentonite at temperatures up to $200^{\circ} \mathrm{C}$ improves cationexchange of HM ability of montmorillonite. The degree of extraction of HM ions in the case of using thermally activated bentonite is for $\mathrm{Cu}^{2+}-65,6 \%, \mathrm{~Pb}^{2+}-74,9 \%, \mathrm{Cd}^{2+}$ 48,7\%, $\mathrm{Zn}^{2+}-67,1 \%$ (Table 3).

Table 2. The degree of extraction of heavy metal ions in the presence of bentonite in a natural and activated forms mine water

\begin{tabular}{|c|c|c|c|c|c|c|c|c|}
\hline \multirow[b]{3}{*}{ 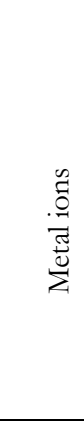 } & \multicolumn{5}{|c|}{$\mathrm{HM}$ ions concentration, $\mathrm{mg} / \mathrm{dm}^{3}$} & \multicolumn{3}{|c|}{ Degree of extraction, $\mathrm{A} \%$} \\
\hline & \multirow[b]{2}{*}{ 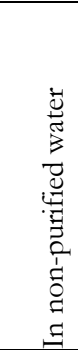 } & \multicolumn{4}{|c|}{$\begin{array}{l}\text { In purified water in the presence of } \\
\text { bentonite }\end{array}$} & \multirow[b]{2}{*}{$\begin{array}{l}\bar{\Xi} \\
\text { Е } \\
\text { Z }\end{array}$} & \multirow[b]{2}{*}{ 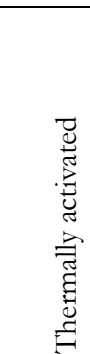 } & \multirow[b]{2}{*}{ 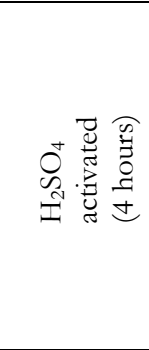 } \\
\hline & & 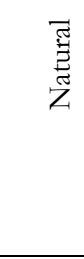 & 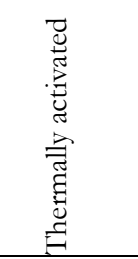 & 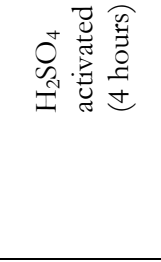 & 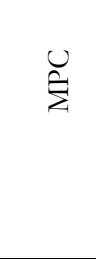 & & & \\
\hline $\mathrm{u}^{2+}$ & ,21 & ,14 & 0,07 & $\begin{array}{ll} & 0 \\
, 001 & \end{array}$ & ,001 & 3,3 & 5,6 & 9,6 \\
\hline $\mathrm{b}^{2+}$ & 11 & ,09 & 0,03 & 01 &, 10 & 8,2 & 4,9 & 4,7 \\
\hline $\mathrm{d}^{2+}$ & 17 & ,14 & 0,09 & ,006 &, 005 & 7,6 & 8,7 & 8,9 \\
\hline $\mathrm{n}^{2+}$ & 2,3 &, 70 & 4,03 & ,01 & ,01 & 9,2 & 7,1 & 9,5 \\
\hline
\end{tabular}

It is known that when montmorillonite is heated exchangeable cations are dehydrating and start migrating, penetrating into the octahedral of crystal lattice of the mineral, attenuated due Substituting Al - O, gradually, with a further increase in temperature, freeing $\mathrm{Al}$ from octahedral environment $[7,9]$.

Vacant $\mathrm{Al}^{3+}$, being very active, is isomorphic to replace $\mathrm{Si}^{4+}$ from oktaedparameter in the tetrahedral environment that followed the liberation of heat, ie ekzoeffect, as the interatomic distance of $\mathrm{Al}$ - $\mathrm{O}$, octahedra in $\mathrm{A}$ was equal to $1.8-2.0^{\circ}$, and in tetrahedral coordination, it decreased and became equal to 1.6-1.8 $\mathrm{A} \circ$. By law electrostatic attraction, the energy liberated in the interaction of oppositely charged bodies directly proportional to the decrease in distance [8-10].

This exothermic process of the role of exchangeable cations is isomorphic to drive $\mathrm{Al}^{3+}$ from octahedral configuration and compensate for the negative central charge appearing in the isomorphous substitution of $\mathrm{Si}^{4+}$ in the tetrahedra in the $\mathrm{Al}^{3+}[3,4]$. When is the Coy-activated bentonite hydrogen ions displace exchangeable cations sodium, calcium, magnesium exchange positions, but also penetrate into the interior of the structure of montmorillonite, attacking communications $\mathrm{Me}$ - About $\mathrm{Me}$ in the fragment-O-Si $[7,8,10]$.

The use of bentonite in the purification acid-activated MPC provides a virtually complete extraction of the ions $\mathrm{HM} \mathrm{Cu}^{2+}, \mathrm{Pb}^{2+}, \mathrm{Cd}^{2+}, \mathrm{Zn}^{2+}$. This is probably due to the change of the composition of exchangeable cations and the structural characteristics and acid-activated bentonite samples. 
Table 3. Composition of exchangeable cations and structural characteristics of the natural and the bentonite samples acidreactive

\begin{tabular}{|c|c|c|c|c|c|c|c|c|}
\hline \multirow[t]{3}{*}{ Bentonite } & \multicolumn{6}{|c|}{$\begin{array}{l}\text { Proportions of exchangeable cations, } \\
\text { mg-equivalent } / 100 \mathrm{~g}\end{array}$} & \multirow{3}{*}{$\begin{array}{l}\mathrm{BET} \\
\mathrm{m}^{2} / \mathrm{g}\end{array}$} & \multirow[t]{3}{*}{, $\mathrm{cm}^{3} / \mathrm{g}$} \\
\hline & \multirow[b]{2}{*}{$\mathrm{a}^{+}$} & \multirow[b]{2}{*}{$a^{2+}$} & \multirow[b]{2}{*}{$g^{2+}$} & \multicolumn{2}{|c|}{ Exchange acidity } & \multirow[t]{2}{*}{ Total } & & \\
\hline & & & & + & $1^{3+}$ & & & \\
\hline natural & 25,9 & 42,9 & 27,8 & - & - & 96,6 & 90 & 0,09 \\
\hline $10 \% \mathrm{H}_{2} \mathrm{SO}_{4}$ activated & 0,50 & 2,18 & 7,21 & 0,67 & 53,82 & 64,38 & 200 & 0,36 \\
\hline
\end{tabular}

Table 3 shows that dramatically changed the chemical nature of activated bentonite $10 \% \mathrm{H}_{2} \mathrm{SO}_{4}$. The surface becomes acidic due to the exchange-governmental centers acidic hydrogen ions, thus releasing some quantity of silica, which leads to an increase in the surface of the activated hinges are 2-4 times as compared with the surface of non-activated hinges. Acid-activation did not change from the prevailing pore size of initial bentonite, however, leads to the appearance of large pores and transient increase in the porosity of the hinge. All these factors lead to an increase in sorption capacity of the A,\% hinge [8-10].
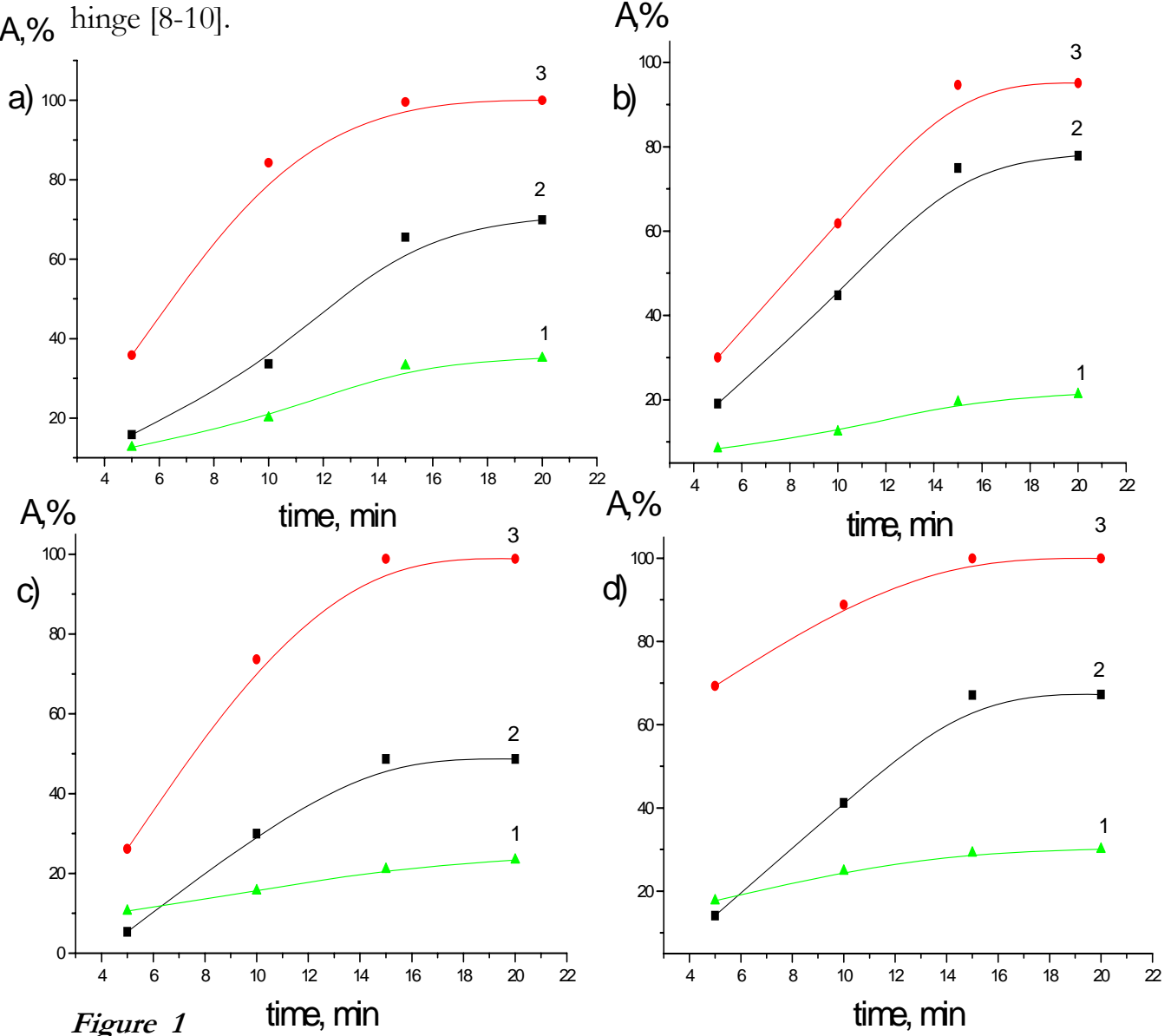

Bentonite: The degree of extraction of metal ions, from the time of contact:

$a$-copper, $b$-lead, $c$-cadmium, $d$ - zinc. 1 - in its natural state, 2 - thermal activation 3-sulfuric acid activation $\left(10 \%-\mathrm{H}_{2} \mathrm{SO}_{4}\right.$ for 4 - hours). 
The contact time with the bentonite mine water ranges from 5 to 30 minutes. The results show that the optimal time of extraction of ions from the TM of mine water is 15 minutes.

Table 4. Effect of hinge mass of bentonite (a natural, thermal, sulfuric) on the degree of extraction of heavy metal ions

\begin{tabular}{|c|c|c|c|c|c|c|c|c|c|c|c|c|}
\hline \multirow[b]{3}{*}{ 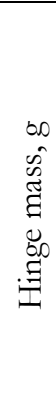 } & \multicolumn{12}{|c|}{ Degree of HM ions extraction, A \% } \\
\hline & \multicolumn{3}{|c|}{$\mathrm{Cu}^{2+}$} & \multicolumn{3}{|c|}{$\mathrm{Pb}^{2+}$} & \multicolumn{3}{|c|}{$\mathrm{Cd}^{2+}$} & \multicolumn{3}{|c|}{$\mathrm{Zn}^{2+}$} \\
\hline & 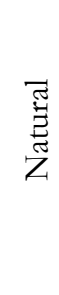 & 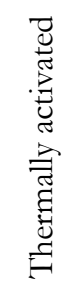 & 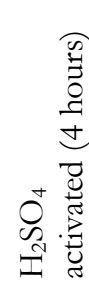 & 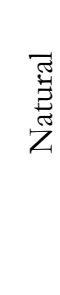 & 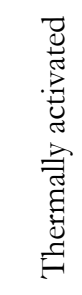 & 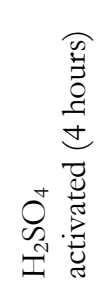 & 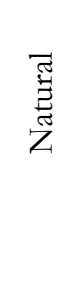 & 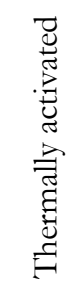 & 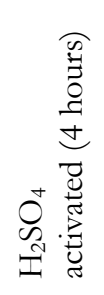 & $\begin{array}{l}\overline{\widetilde{\pi}} \\
\text { 总 } \\
\text { Z }\end{array}$ & 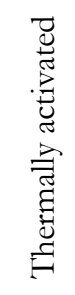 & 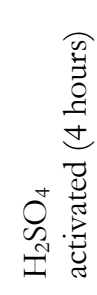 \\
\hline ,1 & 6 & 6,8 & ,8 & 9 & 9,1 & 0,0 & 0,6 & 4 & 6,2 & 7,7 & 4,2 & 9,3 \\
\hline , & ,1 & ,6 & 4,3 & 2,4 & 4,8 & 1,8 & 5,6 & 0 & 3,2 & 4,8 & 8,4 & 8,8 \\
\hline ,3 & , 2 & ,6 & 9,6 & 9,5 & 4,9 & 4,7 & 1,0 & 8,7 & 8,9 & 9,2 & 7,1 & 9,9 \\
\hline, 5 & , 0 & 6 & 9,6 & 1,2 & 7,9 & 5,1 & 3,4 & 8,7 & 8,9 & 0,1 & 7,3 & 9,9 \\
\hline
\end{tabular}

The results show that even at $0.6 \%$ rated flow rate of reactive sulfuric acid bentonite ions $\mathrm{Cu}^{2+}, \mathrm{Pb}^{2+}, \mathrm{Cd}^{2+}, \mathrm{Zn}^{2+}$ is almost completely extracted, while the bentonite in a natural and thermally activated state at $1.0 \%$ rated flow rate does not provide reducing the concentration of these ions to the level of MPC.

It should be noted that simultaneously with the change of chemical composition is changing its physical structure, accompanied by the formation of extra-porosity, higher specific surface area and sorption capacity, which correspond to the growth-mode sorption capacity of the sample [3-7, 13, 14].

Cation exchange in this case can be expressed by micellar following Equation:

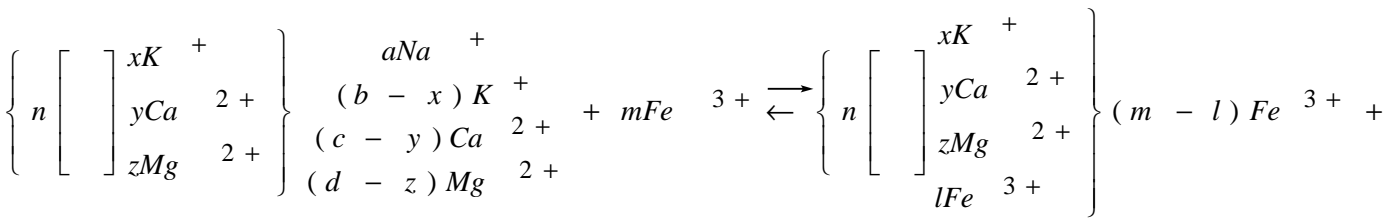

$$
\begin{aligned}
& +a N a++(b-x) K^{+}+(c-y) C a^{2+}+(d-z) M g{ }^{2+} ; \\
& n=a+b+c+d ; \quad m=n-(x+y+z),
\end{aligned}
$$

where the coefficients indicate the number of equivalents of the cations. The magnitude of the exchange capacity is equivalent to the number entered into an exchange of ions 
$\mathrm{Fe}^{3+}$, which is determined by the difference of their content in the solution before and after the exchange photocolorimetric-profit sulfosalicylic method.

\section{Conclusions}

On the basis of experimental data, we can conclude that the best sorbent for the extraction of heavy metal ions $\mathrm{Cu}^{2+}, \mathrm{Pb}^{2+}, \mathrm{Cd}^{2+}, \mathrm{Zn}^{2+}$ in the mine water is bentonite 14bedrock of the Tagansky deposits of the East Kazakhstan region the last heat treatment at $200^{\circ} \mathrm{C}$, followed by activation of $10 \%$ - sulfuric acid for 4 hours at the selected optimal conditions: $\mathrm{pH}$ 8.0-8.5, mixing time $15 \mathrm{~min}, 1.0 \%$ bentonite flow rate allows the shaft to clean water to the level of standards established by the MPC fish - economicpurpose.

\section{References}

V.N. Startsev, Skorikova E.P. The process and the scheme of treatment of mine waters in the mining of polymetallic ores / / Technological. aspects of the circle. medium in color. metallurgy. - 1990. - № 3. - P. 88-93.

Gudkov, NN, LN Kornyakova The method of sewage treatment from ions of heavy metals and nonferrous metals calcium carbonate / / commit. Eng. equip. buildings and structures / gos.tehn Chelyabinsk. University. - Chelyabinsk, 1990. - P. 104-112.

U.S. Patent 5013453, MKI C02 F 1/52. Method of extraction of heavy metals from aqueous media by coprecipitation / Walker Dauglas T. - Publ. 07.05.91.

Zapolsky A.TS., Baran A. Coagulants and flocculants in water treatment processes. - L., 1987. - P.204.

Belyavtsev A. Natural sorbents in the purification process of waste water / / water supply. and dignity. Technical. - 1983. - № 11. - P. 5-7.

Battalova Sh.B. Physico-chemical bases of production and application of catalysts and adsorbents of bentonite. - Alma-Ata, 1986. - P.168.

Deer WA, Howie RA, Zussman J.. Rock-forming minerals. MA, 1966

Merabishvili MS On integrated production of activated sorbents from bentonite and sulfuric acid salts of aluminum / / Proceedings of the III All-Union Conference on the adsorbents. - L., 1971. - P. 280.

Brigatti Maria Franca, Franchini Glancar, Frigieri Paola, Gardincl Christian, Vedici Luca, Poppi Luciana. Treatment of industrial Wlate water using ztolitite and sepiolite, natural microporous materials / / Can. J. Chem. Eng. - 1999. - V. 77, № 1. - P. 163-168.

Muzdybayeva S.A., Teut E.V. Colloid-chemical treatment of mine water from the polymetallic deposit of heavy metal ions $\left(\mathrm{Cu}^{2+}, \mathrm{Pb}^{2+}, \mathrm{Cd}^{2+}, \mathrm{Zn}^{2+}\right) / /$ Bulletin of $\mathrm{KNU}$ chemical series. - 2012. - № 1 (165). - P. 305-308. 